\title{
CEREBRAL ISCHAEMIA AND STROKE; ROLE OF CAROTID DOPPLER
}

1. MBBS, DIP Radiology Radiologist PAF Hospital Lahore.

2. MBBS, FCPS (Med), FACP Medical Specialist PAF Hospital Lahore.

3. MBBS, Dip

(Hospital Admin \& Management) PAF Hospital Lahore.

4. MBBS, FCPS

Asst: Professor Bio Chemistry HITEC IMS Taxila.

5. MBBS, FCPS

Asst: Professor of Medicine PAF Hospital Islamabad.

Correspondence Address:

Dr. Naveed Aslam Lashari

MBBS, FCPS

Medical Specialist

PAF Hospital Lahore,

Munir Road Lahore Cantt.

lasharinaveed@hotmail.com

Article received on:

25/04/2017

Accepted for publication:

15/09/2017

Received after proof reading:

$29 / 11 / 2017$

\begin{abstract}
Sibghat Ullah Khan ${ }^{1}$, Naveed Aslam Lashari ${ }^{2}$, Nadia Irum Lakho ${ }^{3}$, Ambreen Faisal ${ }^{4}$, Aamir Hussain ${ }^{5}$
\end{abstract}
ABSTRACT... Introduction: Colour Doppler sonography is a well-established widely available, noninvasive, cost effective and a reliable method for assessing cerebrovascular circulation. It has become a valuable completion of the sonographic workup in patients with cerebral ischaemia and infarction. Its accuracy is close to angiography. Objectives: To determine the frequency of significant carotid artery stenosis in patients of cerebral ischaemia/stroke and its characterized sonographic appearance of plaque. Study Design: Cross sectional study, based on nonprobability convenience sample technique. Setting: Department of Radiology, Combined Military Hospital Lahore, using Colour and Power Doppler Ultrasound machine ALOKA SSD5500. Period: 14 October 2006 to 15 March 2007. Methodology: Total of 50 diagnosed patients of either gender, aged 30 to 70 years with cerebral ischaemia and stroke were included in the study. Carotid Doppler examination was conducted in each patient and findings were recorded. Results: Among 50 patients who underwent carotid Doppler examination for diagnosis of clinically significant carotid artery stenosis, 35 patients had carotid plaques. 08 patients were diagnosed to have more than $70 \%$ stenosis, 07 patients with more than $50 \%$ and 20 patients less than $50 \%$ carotid artery stenosis. 15 patients did not show any carotid artery disease. 12 patients had bilateral stenosis while 23 had unilateral disease. Mean age of the patients with and without carotid artery disease was $52 \pm 7.87$ years. Conclusion: Majority of patients with Cerebral ischemia/stroke showed carotid artery stenosis on colour Doppler ultrasound. Common age group who developed cerebral ischemia/stroke was above 50years.

Key words: Colour Doppler Sonography, Carotid Duplex Ultrasound, Cerebral Blood Flow, Cerebral Ischaemia, Stroke, Doppler Criteria, Carotid Arteries, Vertebral Arteries, Stenosis, Doppler Ultrasound Machine ALOKA SSD-5500.

Article Citation: Khan S, Lashari NA, Lakho NI, Faisal A, Hussain A. Cerebral ischaemia and stroke; Role of carotid Doppler. Professional Med J 2017;24(12):18231827. DOI:10.17957/TPMJ/17.4001

\section{INTRODUCTION}

Atherosclerotic lesions in extra cranial arteries cause significant proportion of ischemic strokes, ${ }^{1}$ However disease at carotid bifurcation is important cause of cerebral ischemic stokes and its symptoms but other factors like hypertensive episodes, cardiac arrhythmias, emboli and atheromatous disease anywhere in circulation from heart to intracerebral arteries play vital role in disease process. ${ }^{2}$ The notable level of stenosis at carotid arteries where blood starts to decline is $50 \%$ reduction in its diameter and diverse clinical symptoms appear when stenosis reaches at $70 \%$ and more, which needs surgical stenting. ${ }^{2,3}$ Ultrasonography is a accurate and reliable investigation which quantify the stenosis and predict the morphology of plaque with its obvious associated complications. .,3,4 $^{2, a q u e}$ ulceration is associated with an increase risk of cerebral embolism. Ultrasonography is helpful for detection of plaque ulceration, echogenicity, surface and intraplaque haemorrhage which has prognostic implications in ischemic stroke. .,6,7,8,9,10

Vertebral arteries are responsible for adequate blood flow to brain which can be decreased with significant stenosis and can be assessed with carotid duplex imaging, which is considered as best non-invasive screening test for stenosis in external carotid arteries. ${ }^{11}$ Majority of such patients require endarterectomy for symptomatic relief. Carotid duplex imaging is safe than angiography in preoperative assessment. ${ }^{11}$ It also provides identification of risk of re-stenosis 
postoperatively. ${ }^{12}$ High grade of stenosis in carotid arteries increases focal blood flow velocity which can be detected with safe and inexpensive technique of carotid duplex using B-mode ultrasound imaging and Doppler ultrasound. ${ }^{6,7,8}$ The severity of stenosis is assessed with peak systolic velocity which is considered the most frequent gauge, however spectral configuration, diastolic velocity and internal/common carotid artery ratio provides additional information. ${ }^{13}$ The efficiency of the test may be improved with color Doppler flow technique but the accuracy has not been shown to improve. ${ }^{6,8,14,15}$ The stenosis of internal carotid artery is detected with $91-94 \%$ sensitivity and $85-99 \%$ specificity. ${ }^{6,7,8}$ The purpose of this hospital based study was to characterize the ultrasonographic morphology of plaque and accurately diagnose hemodynamically and clinically significant stenosis of extracranial carotid arteries in patients of cerebral ischaemia and stroke so that unstable plaques and true candidates for endarterectomy could be identified. The study will further encourage the local clinicians and radiologists to use this non invasive, easily accessible and much cheaper modality for diagnosis.

\section{OBJECTIVE:}

To determine the frequency of significant carotid artery stenosis and evaluate the characteristics of plaque on colour and power Doppler ultrasound, in clinically diagnosed cases of cerebral ischaemia/stroke.

\section{METHODOLOGY}

This was a cross sectional study carried out in Department of Radiology, Combined Military Hospital Lahore, using Colour and Power Doppler Ultrasound machine ALOKA SSD-5500 from 14 October 2006 to 15 March 2007. A total of 50 diagnosed patients of either gender, aged 30 to 70 years with cerebral ischaemia and stroke, selected on non-probability convenience sampling were included in the study. Carotid Doppler examination was conducted in each patient. Patients with already known underlying cause of cerebral ischaemia \& stroke other than carotid artery stenosis were excluded from study.
Informed consent was taken from all the eligible patients. Demographics like name, gender, age and address was noted. Cerebral infarction was confirmed by plain CT scan of head and hemorrhagic strokes were excluded from study.

After taking detailed history regarding pattern of development of stroke, any risk factor and investigations, Carotid Doppler ultrasound of neck arteries was done and patients were placed in different categories according to degree of carotid arteries stenosis. Treatment was offered according to initial diagnosis.

\section{Statistical Analysis}

Data were entered and analyzed using statistical package SPSS version 11 for analysis. The variables to be analyzed included demographic information and degree of carotid artery stenosis. Mean and standard deviations were calculated accordingly for numerical data and frequency and percentage was calculated for qualitative data. Findings on Carotid Doppler were presented as frequency and percentage. Specific variables were made associated with basic variables by applying chi-square test as the data was mainly of qualitative nature. P-value of equal to or less than 0.05 was taken as significant.

\section{RESULTS}

Out of 50 patients majority $28(56 \%)$ were males and $22(44 \%)$ were female. Mean ( $\pm S D$ ) age of the patient was $52 \pm 7.87$ years. After Doppler ultrasonography 35 (70\%) patient were diagnosed to have plaques involving carotid vessels, the frequency of unilateral and bilateral plaque is shown in Figure-1. 15 (30\%) patients did not show plaque formation in extracranial vessels. Out of the 35 patients with plaque formation, 8 patients showed $>230 \mathrm{~cm} / \mathrm{sec}$ peak systolic velocity at the site of stenosis caused by plaque formation accounting more than $70 \%$ of stenosis, 7 had peak systolic velocity ranging from 125-230 $\mathrm{cm} / \mathrm{sec}$ accounting more than $50 \%$ of stenosis and 20 , less than $125 \mathrm{~cm} / \mathrm{sec}$ showing less than $50 \%$ of stenosis (Table-I). Out of these 35 patients $18(51.42 \%)$ were having plaques in carotid bulb region, 12 (34.28\%) in proximal part of internal carotid artery and 5 (14.28\%) patients in distal 
part of common carotid artery just proximal to carotid bulb, demonstrating carotid bulb to be the common site for plaque formation.

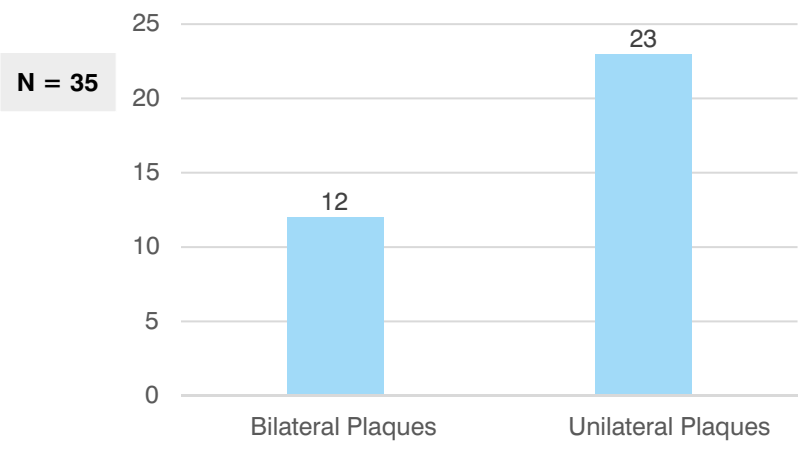

Figure 1. Frequencies of unilateral/bilateral plaques

\begin{tabular}{|c|c|c|}
\hline S. No & $\begin{array}{c}\text { Diameter percentage stenosis in } \\
\text { carotid vessels with velocities }\end{array}$ & $\begin{array}{c}\text { No of } \\
\text { Patients }\end{array}$ \\
\hline 1 & $>70 \%>230 \mathrm{cms} / \mathrm{sec}$ & 08 \\
\hline 2 & $>50 \%>125-230 \mathrm{cms} / \mathrm{sec}$ & 07 \\
\hline 3 & $<50 \%<125 \mathrm{cms} / \mathrm{sec}$ & 20 \\
\hline \multicolumn{2}{|c|}{$\begin{array}{c}\text { Table-I. Frequency distribution of grades of carotid } \\
\text { artery stenosis }\end{array}$} \\
\hline
\end{tabular}

\section{DISCUSSION}

Many advanced techniques have been developed to detect carotid artery disease, often enabling surgeons to act before plaque progresses to point of occlusion or imminent stroke.

Carotid artery angiography is investigation of choice in quantifying the degree of stenosis but several inaccuracies are noted like observers variations in measurement and use of multiple imaging planes which may miss maximum stenosis. ${ }^{14}$ Although it has been reported that duplex US findings can be even more precised than angiographic findings ${ }^{15}$, the experiences from the NASCET (North American Symptomatic Carotid Endarterectomy Trial) and the Committee for the Asymptomatic Carotid Atherostenosis provide the rationale for performing carotid artery surgery, evolved from stenosis diameter measurements on angiograms. Which shows that the diameter of a stenosis measured at angiography remains the reference standard. ${ }^{16}$ Non invasive technique like carotid duplex USG can confidently be done differentiate clinical relevant stenosis of greater than $50 \%$ stenosis and even better in stenosis more than $70 \%$ with excellent agreement and angiographic finding, although it tend to lead some overestimation in certain grades of stenosis. ${ }^{16}$ The study could have been more better if based on comparison with angiographic findings, but because of the lack of facility of angiography, a descriptive pattern of study was carried out.

In this study quantification of the degree of stenosis is based on carotid artery diameter stenosis and velocity Doppler criteria. PSV measurement was taken at proper sites in ICA and CCA for ratio measurement. PSV in ICA was taken at the site of maximum narrowing and in CCA at straight mid to distal segment. The recently published recommendations by the Society of Radiologists in Ultrasound advocate the use of a PSV threshold of $230 \mathrm{~cm} / \mathrm{s}$ for diagnosing a $70 \%$ to $99 \%$ diameter stenosis. ${ }^{18}$ Application of this threshold to our data resulted in good overall diagnostic accuracy based on comparing the degree of stenosis by PSV threshold to that by direct measurement. Differentiation of high grade stenosis from complete occlusion of ICA was quite easy by the use of colour and power Doppler. In patients with carotid stenosis, the commonest location was carotid bifurcation/carotid bulb. Evaluation of plaque location is an important part of the standard carotid duplex sonographic examination. ${ }^{17}$ In our study, carotid ultrasound approximately accurately localized the site of plaque and luminal narrowing. All 35 patients with plaque formation also showed increased intima media thickness (IMT). An association between brain infarction (BI) and CCA-IMT was established in a case-control study, the Rotterdam study. ${ }^{19}$ The increase IMT and focal plaques have almost common atherosclerotic risk factors, this suggests that either both are dependent or at least share same pathological process. ${ }^{20}$ The mean age of acquiring cerebral ischemia and stroke in our study was around $52 \pm 7.87$ years, which was lower than 57.5 years reported by Akhtar ${ }^{21}$ and much lower than 70 years in United States. ${ }^{22}$ This difference is possibly because of better awareness and control of risk factors in United States or shorter life span in Pakistan as compared to 
Western countries. ${ }^{23}$ The lack of correspondence of few results of our study to international studies might be due to small sample size, relatively short span of study and probably also because of the patients of specific age range, included in the study. In spite of the fact that Doppler ultrasound is a non-invasive imaging modality of choice in evaluation of extra-cranial carotid artery disease, like any other imaging modality it has certain pitfalls \& limitations which are mostly technical and operator dependent. We found difficulty in examining patients having thick neck and high bifurcation of CCA. Similarly tortuous vessels were also noticed to lead to turbulence of flow with false increase in peak systolic velocity. In such cases measurements are recommended to be taken at the straight segment of the vessels to get accurate results.

\section{CONCLUSION}

Colour Doppler sonography is nowadays the first imaging examination performed for the diagnosis of carotid artery stenosis. Its dual ability to evaluate both morphologic and hemodynamic abnormalities and cost-effectiveness make Colour Doppler ultrasound as the only test applied before a therapeutic decision. A standardized protocol of examination, knowledge, experience among operators and imaging specialists and a continuous quality control are necessary to ensure reliable results because carotid arterial Doppler examination is a dedicated procedure and gets affected by deviation from standard protocol. Other than conventional angiography, computed tomographic angiography (CTA), magnetic resonance angiography (MRA) and digital subtraction angiography (DSA) can be used for definitive diagnosis in patients with discrepant clinical and duplex sonographic findings, however these are expensive and invasive tests.

\section{Copyright@ 15 Sep, 2017.}

\section{REFERENCES}

1. Kablak-Ziembicka A, Przewlocki T, Pieniazek P, Musialek P, Motyl R, Rudko R et al. Evaluation of cerebral circulation in patients with significant carotid artery stenosis. Kardiol Pol 2005 Oct; 63: 381-89.

\section{Allan PA. The carotid and vertebral arteries and Trans}

cranial color Doppler. Clinical Doppler ultrasound. $1^{\text {st }}$ ed. Philadelphia: Elsevier science limited. 2003; 39-56.

3. Sutton D, Text Book of Radiology and Imaging Volume I. $7^{\text {th }}$ ed. China: Churchill Livingstone; 2003; 461-64.

4. Gautier C, Lecher X, Pruvo JP et al. The role of carotid and transcranial Doppler sonography in the management of ischaemic stroke. J Radiol 2005; $86: 1105-14$.

5. O'Donnell RF, Erodes L, Mackey WC, et al. Correlation of B-mode ultrasound imaging and arteriorgraphy with pathologic findings at carotid endarterectomy. Arch Surg 1985; 120:443-48.

6. Carroll BA. Carotid sonography. Radiology 1991; 178:303-13.

7. Tsuruda JS, Saloner D, Anderson D. Noninvasive evaluation of cerebral ischemia. Trends for the 1990s. Circulation 1991; 83: -176-89.

8. Zwiebel WJ. Duplex sonography of the cerebral arteries: efficacy, limitations, and indications. AJR 1992; 158:29-36.

9. Ammar $A D$, et al. Incidence of bilateral intraplaque hemorrhage in carotid artery disease. Cardiovasc Surg 1993; 1:717-19.

10. Langsfeld M, Gray-Weale AC, Lusby RJ. The role of plaque morphology and diameter reduction in the development of new symptoms in asymptomatic carotid arteries. J Vasc Surg 1989; 9:548-57.

11. Zaidi NR, Khan NA, Dodhy K, Mahmood K. Carotid Duplex imaging is better modality than Angiography to diagnose carotid artery stenosis in patients for Endarterectomy. Ann King Edward Med Coll 2004; 10 : 380-3.

12. Hirschl M, Palkovits J, Katzenschlager R et al. Duplex sonographic predictors of restenosis, vascular and neurological events after carotid endarterectomy. Wien Klin Wochenschr 2002; 114: 327-33.

13. Hunink JGM, Polak JF, Barlan MM, O'Leary DH. Detection and quantification of carotid artery stenosis: efficacy of various Doppler velocity parameters. AJR 1992; 160:619-25.

14. Young GR, Humphrey PR, Nixon TE, Smith ET. Variability in measurement of extracranial internal carotid artery stenosis as displayed by both digital subtraction and magnetic resonance angiography. Stroke 1996; 27:467-73.

15. Alexandrov AV, Bladin CF, Maggisano R, Norris JW. Measuring carotid stenosis. Stroke 1993; 24:1292-96. 
16. Sabeti $\mathbf{S}$, Schillinger $\mathbf{M}$, Mlekusch $\mathbf{W}$, Willfort $\mathbf{A}$, Haume Mr, Nachtmann T et al. Quantification of Internal Carotid Artery Stenosis with Duplex US: Comparative Analysis of Different Flow Velocity Criteria. Radiology 2004; 232: 431- 439.

17. Gaitini D and Soudack M. Review Article, Diagnosing Carotid stenosis by Doppler Sonography. State of the Art .2005.J Ultrasound Med 24: 1127- 36.

18. Grant EG, Benson CB, Moneta GL, Alexandrov AV, Baker JD, Blush El et al. Carotid artery stenosis: gray-scale and Doppler us diagnosis-Society of Radiologists in Ultrasound Consensus Conference. Radiology/2003; 229: 340-46.

19. Bots ML, Hoes AW, Coastal PJ, et al. Common carotid intima-media thickness and risk of stroke and myocardial infarction: the Rotterdam Study. Circulation/1997; 96:1432-37.
20. Touboul PJ, Elba A, Koller C, Lucas C, Adraï V, Cherub F et al. Common Carotid Artery Intima-Media Thickness and Brain Infarction. American Heart Association 2000; 102: 313.

21. Akhter W. Stroke: The common modifiable risk factors and inpatient outcome. Dissertation College of Physicians and Surgeons Pakistan (CPSP). Med/ $3510 \mathrm{~A} / 2001$.

22. Sacco RL, Gann R, Boden-Albala B, Lin IF, Kerman DE, Hauser WA et al. Leisure-time physical activity and ischemic stroke risk. The North Manhattan Stroke Study. Stroke 1998; 29: 380-87.

23. Rafique AB, Muhammad $Y$, Javed I, Muhammad MK. Frequency of known risk for stroke in poor patients admitted to Lahore general hospital in 2000. Pak J Med Sci/ 2002; 18: 280-83.

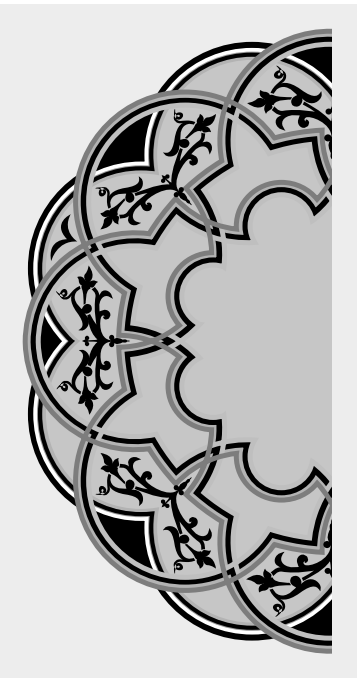

\title{
"Quality mean doing it right when no one is looking."
}

\author{
Henry Ford
}

\section{AUTHORSHIP AND CONTRIBUTION DECLARATION}

\begin{tabular}{|c|l|l|l|}
\hline Sr. \# & \multicolumn{1}{|c|}{ Author-s Full Name } & \multicolumn{1}{|c|}{ Contribution to the paper } \\
\hline 1 & Sibghat Ullah Khan & 1st Author & Author=s Signature \\
2 & Naveed Aslam Lashari & 2md Author \\
3 & Nadia Irum Lakho & 3rd Author \\
4 & Ambreen Faisal & 4th Author \\
5 & Aamir Hussain & 5th Author & \\
\hline
\end{tabular}

